\title{
Characterization and modeling of the polarization phenomenon to describe salt rejection by nanofiltration
}

\author{
Yassine Mdemagh $^{1,3, *}$, Amor Hafiane ${ }^{1}$, Ezzedine Ferjani ${ }^{1,2}$ \\ ${ }^{1}$ Membrane Technology Laboratory, Water Researches and Technologies Centre of Borj-Cedria (CERTE), Technopark of \\ Borj-Cedria, 8020 Soliman, Tunisia \\ ${ }^{2}$ Higher Institute of Sciences and Technologies of Environment of Borj Cedria, University of Carthage, Carthage, Tunisia \\ ${ }^{3}$ Tunisia Faculty Science, Tunis, Tunisia
}

Received 9 February 2018, Accepted 3 October 2018

\begin{abstract}
In this work, dead-end filtration was applied to the nanofiltration of synthetic ionic solutions. In order to study the phenomenon of polarization in the boundary layer, we chose $\mathrm{NaCl}, \mathrm{CaCl}_{2}$ and $\mathrm{Na}_{2}\left(\mathrm{SO}_{4}\right)$ solutions to $\mathrm{pH}=6.8$ which concentrations varies from 0.3 to $1.5 \mathrm{~g} \mathrm{~L}^{-1}$ and the filtration pressure varied from 6 to 16 bar. In this study, the results of these experiments show a correlation between the initial concentration of the solution and the pressure applied with the polarization. The polarization intensifies for the high concentrations and pressures. The ionic balance between the microscopic zone of polarization and the macroscopic state of the solution is described by the following key equation of the model:

$$
\int_{\delta(t)}^{0}\left(C(x, t)-C_{o}\right) \cdot v_{x}(t)=\left(C_{r}(t)-C_{o}\right) \cdot V_{s}(t)
$$

The novelty of this model that it is sufficient to know the conductivity and volume flow of permeate solution to calculate precisely the polarization concentration at the membrane surface, the thickness of the polarization layer and the concentration profile inside the boundary layer polarization. It is important to note that the model developed does not take into account the clogging phenomenon because the experiments were done on low concentration synthetic ionic solutions.
\end{abstract}

Keywords: Nanofiltration, Polarization, New model

\section{Introduction}

Since the advent of membranes, many studies that date back to 1970 have first aimed at improving the comprehension of the phenomenon involved in the clogging, in more or less short term, to be able to anticipate it, even to control it. Different processes have been used for this purpose: one of the most important is nanofiltration [1-8], which is applied as a means of water treatment in several areas [9-14], based on different methods such as electrochimical peroxidation $[15,16]$ and electrocoagulation [17].

These efforts are aimed, on the one hand to identify the elements responsible for clogging, on the other hand, to propose methods of quantification leading to provide indications for improving the conduct of operations. In this context, our study of Master's degree focuses on the first clogging step: it is the phenomenon of polarization.

\footnotetext{
*Corresponding author: yassinemdemagh@yahoo.fr
}

In this case, the main objectives of this research are: (i) the studying of the experimental parameters on a locale scale and their influence on the phenomenon of polarization and (ii) the creation of a new mathematical model by the characterization of the polarization that can be considered as a simple model; which does not require several experimental parameters or sophisticates materials to start it, contrary to others models [18-22] which are sometimes a bit complicated.

\section{Material and methods}

This work was focalized on application of the dead-end filtration to the nanofiltration of synthetic ionic solutions such as $\mathrm{NaCl}, \mathrm{CaCl}_{2}$ and $\mathrm{Na}_{2} \mathrm{SO}_{4}$ at different concentrations $(0.3,0.6,0.9,1.2$, and 1.5$) \mathrm{g} \mathrm{L}^{-1}$ and the filtration pressure varied from 6 to 16 bar. The dead-end filtration experiments were conducted in a laboratory-constructed magnetically stirred cell in dead-end filtration mode. The volume of the cell and the $\mathrm{pH}$ of the solution are respectively $200 \mathrm{~mL}$ and 6.8 . It could be fitted within 


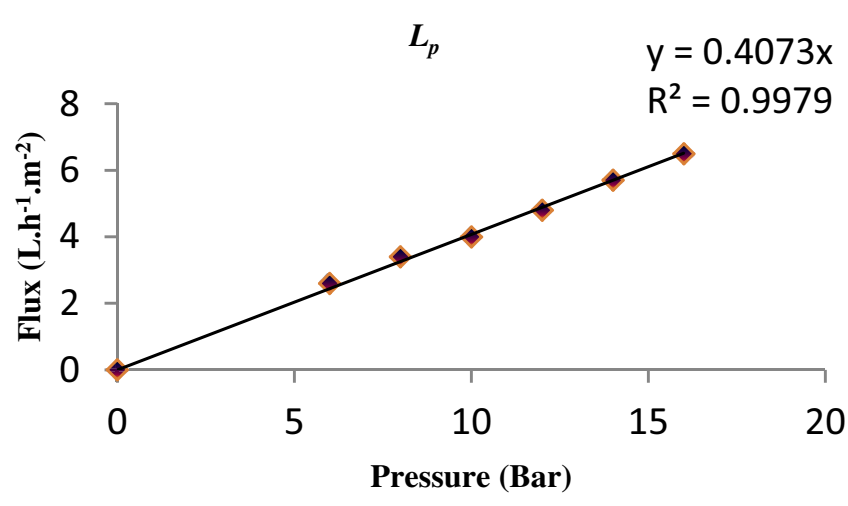

Fig. 1. The permeability coefficient of the membrane UTC- 80 .

the module, with an effective membrane surface area of $38.46 \mathrm{~cm}^{2}$. The membrane used is a UTC-80 (ultra-thin composite) from TORAY.

The membrane is conditioned by the filtration of pure water at the progressive pressure in stages of $20 \mathrm{~min}$ before the tests. The permeability of the membrane is equal to $0.407 \mathrm{~L} \mathrm{~h}^{-1} \mathrm{~m}^{-2} \operatorname{bar}^{-1}$ (Fig. 1).

\section{Procedure of the experiment}

- Fill $200 \mathrm{~mL}$ of the solution into the separation module and adjust the pressure to 6 bar.

- Wait 20 min before the first measurement.

- Collect $5 \mathrm{~mL}$ of permeate, $T_{1}$ is the time necessary to obtain this volume of permeate, the time of the experiment $t_{1}(\mathrm{mn})=20+T_{1}$.

- Measure the conductivity of the permeate solution and calculate the $C_{r 1}$ concentration of the retentate solution with equation (4).

- Without changing the initial solution, set the pressure to the next value of 8 bar and collect $5 \mathrm{~mL}$ of permeate, note also $T_{2}$ and $t_{2}=20+T_{1}+T_{2}$.

- Measure its conductivity and calculate the $C_{r 2}$ concentration of the retentate solution.

- Continue with the same procedure up to 16 bar.

- Fill a new solution of different concentration and repeat the same procedure.

\section{Modelization of concentration polarization}

It should be noticed that in this case, stationary phase cannot be established, and the thickness polarization layer increases from the continuous upcoming ions to theoretically it means the infinity.

\section{Spatial and temporary study of concentration polarization}

The transport equation for species $i$ corresponds to difference between convection upcoming and diffusion departure.

$$
j=J \cdot C-D \cdot \frac{d C}{d x}
$$



Fig. 2. Variation of the retentate concentration as a function of the filtration period $T$.

Fick's second law predicts how the diffusion causes the concentration change with time. It is a one-dimensional partial differential equation:

$$
\frac{d C}{d t}=-\frac{d j}{d x}
$$

Equations (1) and (2) can describe the relation of diffusion concentration in terms of time and spatial differentials:

$$
\frac{\partial C(x, t)}{\partial t}=-J \cdot \frac{\partial C(x, t)}{\partial x}+D \cdot \frac{\partial^{2} C(x, t)}{\partial x^{2}}
$$

After measuring the concentration of the permeate, it will be possible to know indirectly the concentration of the retentate in the module by mass balance:

$$
C_{r}=\frac{C_{b} \cdot V_{b}-C_{p} \cdot V_{p}}{V_{b}-V_{p}}
$$

The filtration of retentate solution $C_{r}$ was applied by varying pressure after every $5 \mathrm{~mL}$ :

$$
C_{r}=\alpha \cdot T^{2}+\beta \cdot T+\gamma
$$

$\alpha, \beta$ and $\gamma$ are constants which are determined from Figure 2. $T$ is the periodic time which is needed to obtain $5 \mathrm{~mL}$ of permeate under the considered pressure. Experimentally, $T$ can be presented as a secondary variation function of time:

$$
T(t)=a \cdot t^{2}+b \cdot t+c
$$

$a, b$ and $c$ are constants which are determined from Figure 3. The variation of the retentate concentration $C_{r}$ of the solution over time is proportional to the variation of the concentration $C(x, t)$ in the boundary layer's polarization.

The variation of $C_{r}$ during the experience is illustrated simultaneously from the graphs of Figures 2 and 3 . 
Table 1. The experimental values.

\begin{tabular}{|c|c|c|c|c|c|c|c|c|}
\hline \multirow[t]{2}{*}{$C_{o}\left(\mathrm{~g} \mathrm{~L}^{-1}\right)$} & \multicolumn{2}{|c|}{0.3} & \multicolumn{2}{|c|}{0.9} & \multicolumn{2}{|c|}{1.2} & \multicolumn{2}{|c|}{1.5} \\
\hline & Min & Max & Min & Max & Min & Max & Min & Max \\
\hline$\overline{\frac{d}{d t} C_{r}(t)}$ & $1.00 \mathrm{E}-06$ & $5.00 \mathrm{E}-06$ & $8.80 \mathrm{E}-07$ & $6.50 \mathrm{E}-06$ & $6.70 \mathrm{E}-06$ & $1.50 \mathrm{E}-05$ & $5.50 \mathrm{E}-06$ & $2.63 \mathrm{E}-05$ \\
\hline$J$ & $6.70 \mathrm{E}-07$ & $1.40 \mathrm{E}-06$ & $5.90 \mathrm{E}-07$ & $1.20 \mathrm{E}-06$ & $5.80 \mathrm{E}-07$ & $1.20 \mathrm{E}-06$ & $5.70 \mathrm{E}-07$ & $1.10 \mathrm{E}-06$ \\
\hline$C_{r}-C_{o}$ & 0.02 & 0.06 & 0.03 & 0.1 & 0.03 & 0.12 & 0.05 & 0.17 \\
\hline$l$ & $4.40 \mathrm{E}-02$ & $5.00 \mathrm{E}-02$ & $4.40 \mathrm{E}-02$ & $5.00 \mathrm{E}-02$ & 4.40E-02 & $5.00 \mathrm{E}-02$ & $4.40 \mathrm{E}-02$ & $5.00 \mathrm{E}-02$ \\
\hline$I$ & $5.74 \mathrm{E}-08$ & $3.34 \mathrm{E}-07$ & $5.64 \mathrm{E}-08$ & $4.45 \mathrm{E}-07$ & $3.12 \mathrm{E}-07$ & $8.94 \mathrm{E}-07$ & $2.71 \mathrm{E}-07$ & $1.50 \mathrm{E}-06$ \\
\hline$T$ & $1.06 \mathrm{E}+03$ & $1.93 \mathrm{E}+03$ & $1.03 \mathrm{E}+03$ & $2.17 \mathrm{E}+03$ & $1.07 \mathrm{E}+03$ & $2.25 \mathrm{E}+03$ & $1.38 \mathrm{E}+03$ & $2.17 \mathrm{E}+03$ \\
\hline$\frac{\partial}{\partial t} C(x, t) \cdot T$ & $6.06 \mathrm{E}-05$ & $6.44 \mathrm{E}-04$ & $5.83 \mathrm{E}-05$ & $9.65 \mathrm{E}-04$ & $3.35 \mathrm{E}-04$ & $2.01 \mathrm{E}-03$ & $3.73 \mathrm{E}-04$ & $3.26 \mathrm{E}-03$ \\
\hline
\end{tabular}

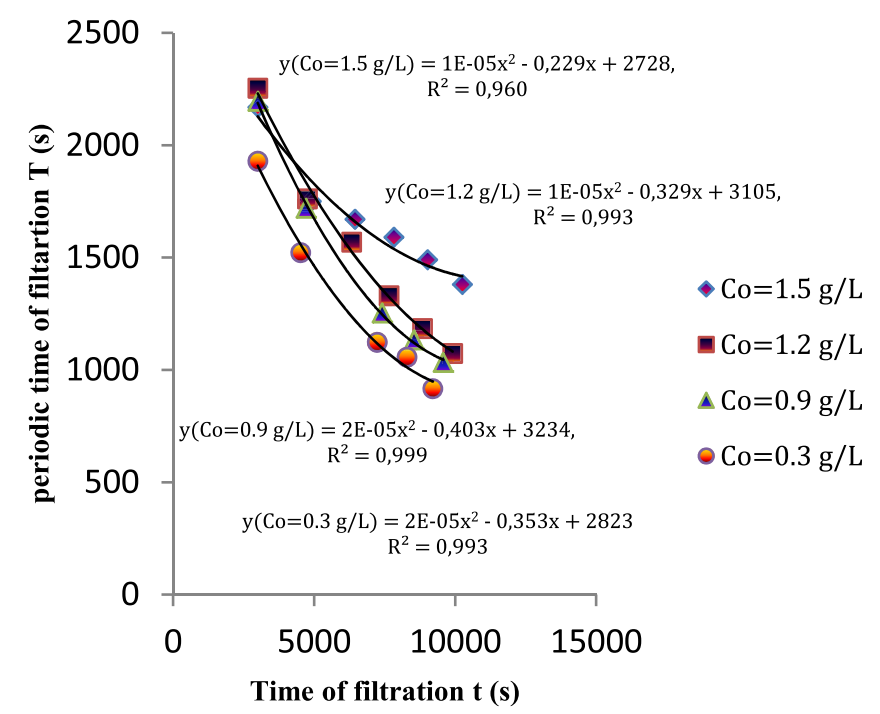

Fig. 3. Variation of filtration periodic $T$ as a function of the filtration time $t$.

The concentration depends on two experimental variables: the time $t$ and the periodic time $T$ of filtration:

$$
\frac{d C_{r}}{d t}=\frac{d C_{r}}{d T} * \frac{d T}{d t}=(2 \alpha \cdot T+\beta) \cdot(2 a \cdot t+b)
$$

The resolution of the mass transfer's equation (3) requires the knowledge of the variation of the concentration in the polarization of boundary layer with time. One of the methods to solve this equation is to subdivide the total filtration time $t$ into smaller intervals $T$ and study the polarization phenomenon over the period $T$. The advantage of this method is to minimize the variation of the concentration over time, it will be shown later in this paper.

During the filtration, there is a mass accumulation in the polarization of boundary layer. This accumulation will modify the total retentate concentration in the solution. The resulting mass balance is given by the equation below:

$$
\int_{\delta}^{0}\left(C(x, t)-C_{o}\right) \cdot v_{x}=\left(C_{r}(t)-C_{o}\right) \cdot V_{s}
$$

Knowing that the function $C(x, t)$ is continuous and bounded on the interval [delta, 0], the integral and the derivative can be permuted:

$$
\begin{aligned}
& \frac{\partial}{\partial t}\left(\int_{\delta(t)}^{0}\left(C(x, t)-C_{o}\right) d x\right) \\
& \quad=\int_{\delta(t)}^{0} \frac{\partial}{\partial t} C(x, t) d x-\left(\frac{d}{d t} \delta(t)\right) \cdot\left(C(\delta(t))-C_{o}\right)
\end{aligned}
$$

with $C(\delta(t), t)=C_{o}, v_{x}=S \cdot d x$ and $V_{s}=S \cdot l$

With equation (8) the result is as follows:

$$
\begin{aligned}
I & =\int_{\delta}^{0} \frac{\partial}{\partial t} C(x, t) d x \\
& =\frac{1}{S}\left(\left(C_{r}-C_{o}\right) \cdot \frac{d}{d t}\left(V_{s}\right)+V_{s} \cdot \frac{d}{d t} C_{r}(t)\right) \\
& =\left(C_{r}-C_{o}\right) \cdot J+l \cdot \frac{d}{d t} C_{r}(t)
\end{aligned}
$$

The experimental values of each term in this equation are illustrated from Table 1 . This table illustrated the minimum and the maximum value.

$$
\begin{aligned}
I= & \int_{\delta}^{0} \frac{\partial}{\partial t} C(x, t) d x \\
& \leq \max \left(\left(C_{r}(t)-C_{o}\right) . J+l . \frac{d}{d t} C_{r}(t)\right) \\
= & 1.5 \times 10^{-6} \mathrm{~g} \mathrm{~L}^{-1} \mathrm{~s}^{-1}
\end{aligned}
$$

It is important to note that the notion of integral of a function is its algebraic sum on the integration interval; in this case, the derivative of the concentration $C(x, t)$ is positive by the mass accumulation effect.

Therefore, necessarily $\forall x_{o} \in[\delta, 0]$ :

$$
\frac{\partial}{\partial t} C(x, t) /_{x=x_{0}} \leq 1.5 \times 10^{-6} \mathrm{~g} \mathrm{~L}^{-1} \mathrm{~s}^{-1}
$$

For a value from a filtration period $T$, we have from Table 1 a maximum variation obtained from this equation:

$$
\frac{\partial}{\partial t} C(x, t) /_{x=x_{0}} \leq 3.26 \times 10^{-3} \mathrm{~g} \mathrm{~L}^{-1}
$$


This result proves that $\frac{\partial}{\partial t} C(x, t) /_{x=x_{0}}$ is approximate and is considered as a limited during the interval $T$. The variation of $C(x, t)$ in time $T$ is negligible.

The problem now is to find a stationary solution for each period $T$. This leads to the following relation:

$$
\frac{d^{2} C}{d x^{2}} \sim \frac{J}{D} \cdot \frac{d C}{d x}
$$

Its solution is described as:

$$
C_{2}(x)=k_{1} \cdot \frac{D}{J} \cdot \exp \left(\frac{J}{D} \cdot x\right)+k_{2}
$$

$k_{1}$ and $k_{2}$ are determined under initial conditions:

$$
\begin{gathered}
x=0 ; C_{2}(x)=C_{m}=\frac{D}{J} \cdot k_{1}+k_{2} \\
x=\delta ; C_{2}(x)=C_{o}=\frac{D}{J} \cdot k_{1} \cdot \exp \left(\frac{J}{D} \cdot x\right)+k_{2}
\end{gathered}
$$

Thus

$$
\begin{gathered}
k_{1}=\frac{C_{o}-C_{m}}{\left(\frac{D}{J}\right) \cdot\left(\exp \left(\frac{J}{D} \delta\right)-1\right)} \\
k_{2}=C_{o}-\frac{C_{m}-C_{o}}{1-\exp \left(\frac{J}{D} \cdot \delta\right)} \cdot \exp \left(\frac{J}{D} \cdot \delta\right)
\end{gathered}
$$

In this case $C_{2}$ is calculated as:

$$
C_{2}(x)=\frac{\left(C_{m}-C_{o}\right) \cdot\left(\exp \left(\frac{J \cdot x}{D}\right)-\exp \left(\frac{J \cdot \delta}{D}\right)\right)}{1-\exp \left(\frac{J \cdot \delta}{D}\right)}+C_{o}
$$

The convection diffusion of the equilibrium boundary thickness can be described as:

$$
J \cdot C_{p}=J \cdot C-D \cdot \frac{d C}{d x}
$$

$C_{1}$ is proposed as a solution of this equation:

$$
C_{1}(x)=k \cdot \exp \left(\frac{J}{D} \cdot x\right)+C_{p}
$$

where $k$ is the constant, under the assumed initial conditions $x=0, C(x)=C_{m}$ we have:

$$
C_{1}(x)=\left(C_{m}-C_{p}\right) \cdot \exp \left(\frac{J \cdot x}{D}\right)+C_{p}
$$

\section{Analytic expression of $C_{m}$ and $\delta$}

Applying initial conditions $C_{1}(\delta)=C_{o}$ in equation (23), we got:

$$
C_{m}=\frac{e^{\frac{J \cdot \delta}{D_{0}}} \cdot C_{p}+C_{o}-C_{p}}{e^{\frac{J . \delta}{D}}}
$$

According to equation (8) we have:

$$
\begin{gathered}
\int_{\delta}^{0}\left(C_{2}(x)-C_{o}\right) \cdot v_{x}=\left(C_{r}-C_{o}\right) \cdot V_{s} \\
\int_{\delta}^{0}\left(C_{2}(x)-C_{o}\right) \cdot S \cdot d x=\left(C_{r}-C_{o}\right) \cdot S \cdot l \\
C_{r}-C_{o}=\frac{1}{l} \cdot \int_{\delta}^{0}\left(C_{2}(x)-C_{o}\right) \cdot d x
\end{gathered}
$$

Assuming the function $H$ as:

$$
H=C_{o}-C_{r}+\frac{1}{l} \cdot \int_{\delta}^{0}\left(C_{2}(x)-C_{o}\right) \cdot d x
$$

For the determination of the expression $H$, we used software "Maple 18".

To calculate $\delta$, we need only to impose that $H=0$.

\section{Selectivity expression}

We can express (Eq. (24)) like as the following relation:

$$
\frac{C_{m}}{C_{p}}=\frac{\frac{C_{o}}{C_{p}}+\left(\exp \left(\frac{J \cdot \delta}{D}\right)-1\right)}{\exp \left(\frac{J \cdot \delta}{D}\right)}
$$

We have also:

$$
R_{\mathrm{obs}}=1-\frac{C_{p}}{C_{o}}
$$

$$
R_{\text {int }}=1-\frac{C_{p}}{C_{m}}
$$

This leads to:

$$
1-R_{\text {int }}=\frac{\exp \left(\frac{J \cdot \delta}{D}\right)}{\frac{1}{1-R_{\mathrm{obs}}}+\exp \left(\frac{J \cdot \delta}{D}\right)-1}
$$

Finally, the rejection estimated with the developed model can be written bellow:

$$
R_{\text {obs }- \text { model }}=\frac{1}{1+\left(\frac{1-R_{\text {int }}}{R_{\text {int }}}\right) \cdot \exp \left(-\frac{J \cdot \delta}{D}\right)}
$$

$$
R_{\text {obs }- \text { model }}=\frac{1}{1+\frac{\exp \left(-\frac{J \cdot \delta}{D}\right)}{C_{m} / C_{p}-1}}
$$

\section{Results and discussion}

\section{Influence of varying the common ion concentration on process parameters}

Flux

For each synthetic solution, the variation of the flux in different pressures is reported in Figures 4-6. 


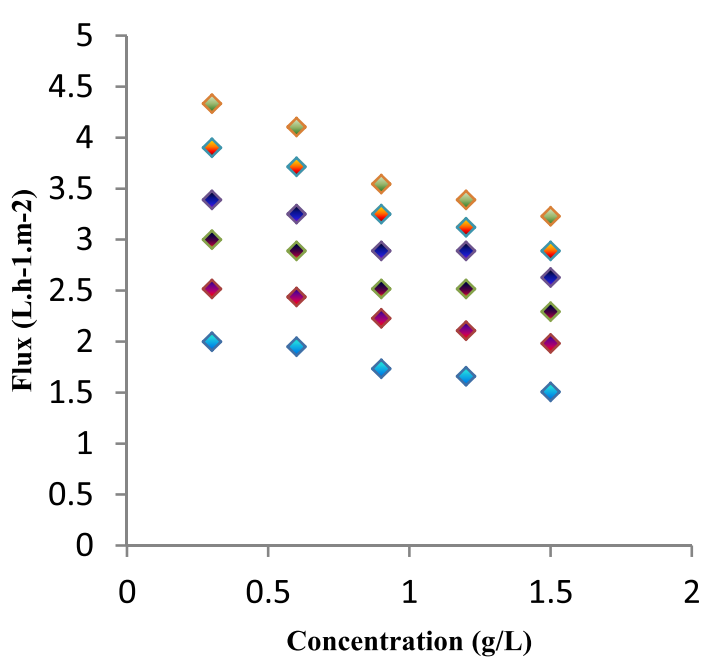

Fig. 4. Variation of flux in the case of $\mathrm{NaCl}$.

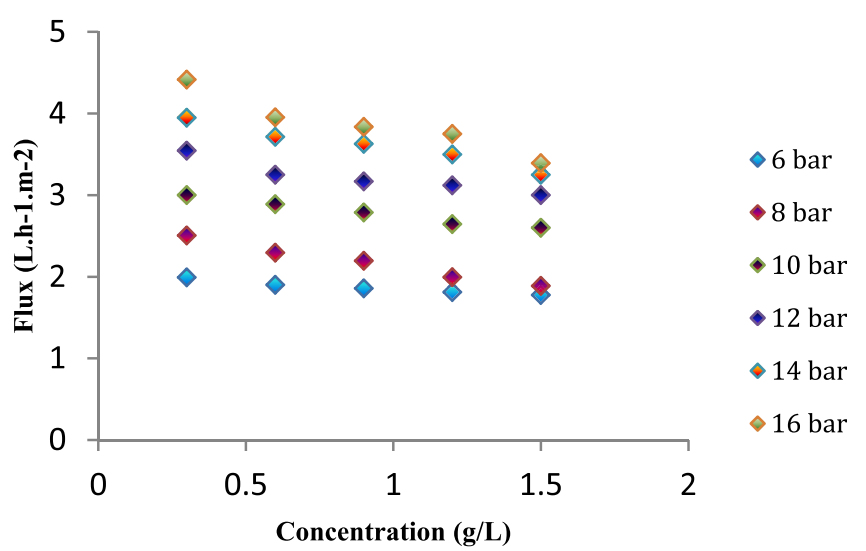

Fig. 5. Variation of flux in the case of $\mathrm{Na}_{2} \mathrm{SO}_{4}$.

The flux variation is the same for the three ions within investigated concentrations. The flux decreases proportionally with the concentration by polarization effect.

\section{Permeability}

Since the hydraulic permeability is an intrinsic specificity of the membrane, we calculated this parameter for all investigated ions with different concentrations. Figure 7 shows that the permeability of $\mathrm{CaCl}_{2}$ is higher than those of $\mathrm{NaCl}$ and $\mathrm{Na}_{2} \mathrm{SO}_{4}$. This is because of the charge's influence of NF membrane is considered [23], which is confirmed with previous results given by Eriksson and Tsuru et al. [24,25]. The little decreasing of permeability can be explained by the interface polarization effect.

\section{Polarization}

Thickness of the boundary layer polarization $(\delta)$

Using the developed numerical model, we have determined in the case of $\mathrm{CaCl}_{2}$, the effect of varying

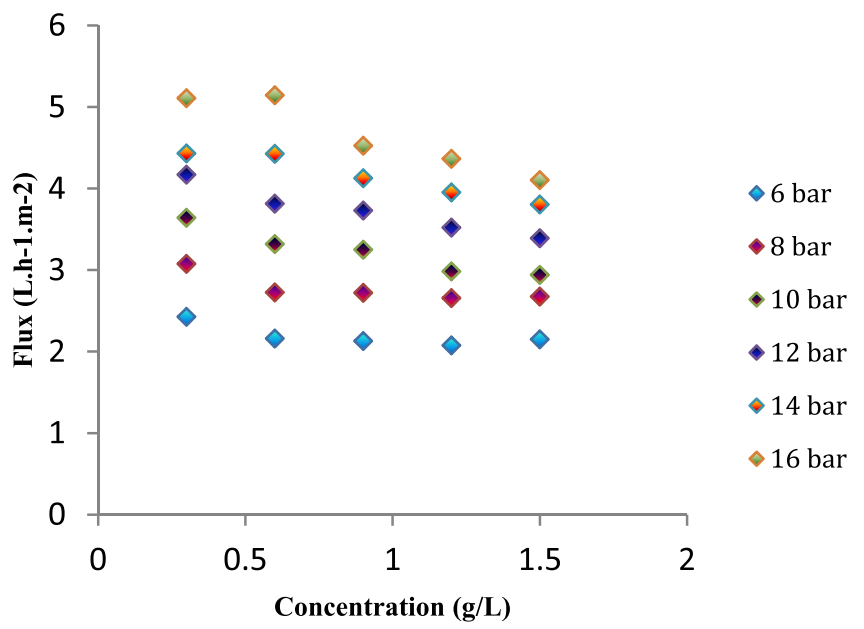

Fig. 6. Variation of flux in the case of $\mathrm{CaCl}_{2}$.

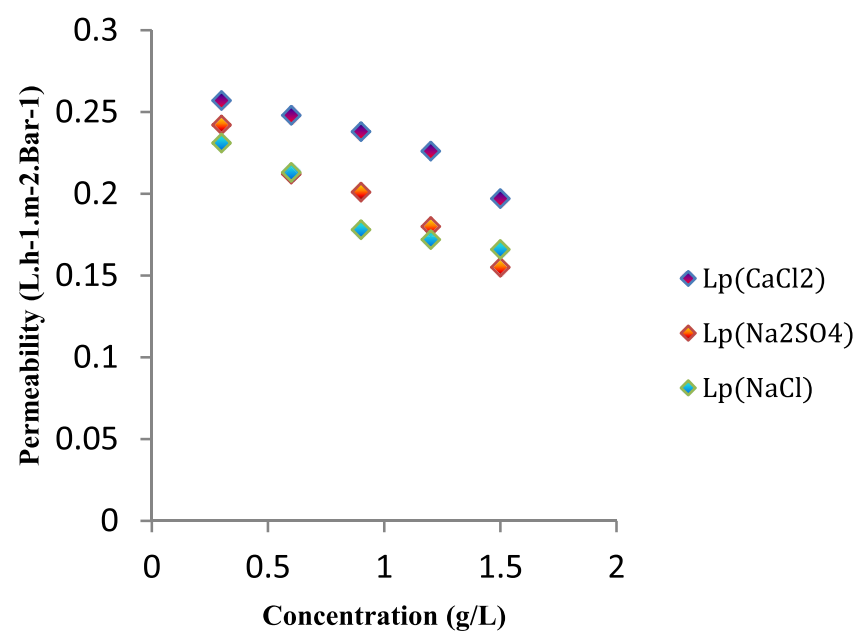

Fig. 7. Variation of permeability with different concentration of salts.

pressures and concentrations on the thickness of the boundary layer's polarization $(\delta)$.

It is clear in Figure 8, with the increasing of the pressure's values during filtration cycle for a given concentration, $\delta$ increases until attending a limit value. This is mainly due to the ion accumulation on polarization layer. These observations can be explained by the existence of two types of interactions: van Der Waals attraction interaction (VDW) (varying as $1 / r^{6}$ ) and electrostatic attractive interaction (which dependent on $1 / r$ ).

Knowing that the energy of electrostatic interaction decreases exponentially as a function of the ionic strength $(\mu)$ of the solution, it allows us to understand that at the highest concentrations these interactions are the weakest so the polarization layer will be more compressible, in addition to the VDW attraction interactions will be stronger in this case since the chemical entities will be closer to each other, hence the values of $\delta$ at low concentrations will be greater. Chaabane et al. confirmed these results [26]. The limited values of $\delta$ for higher pressures were related to repulsive interaction created by 


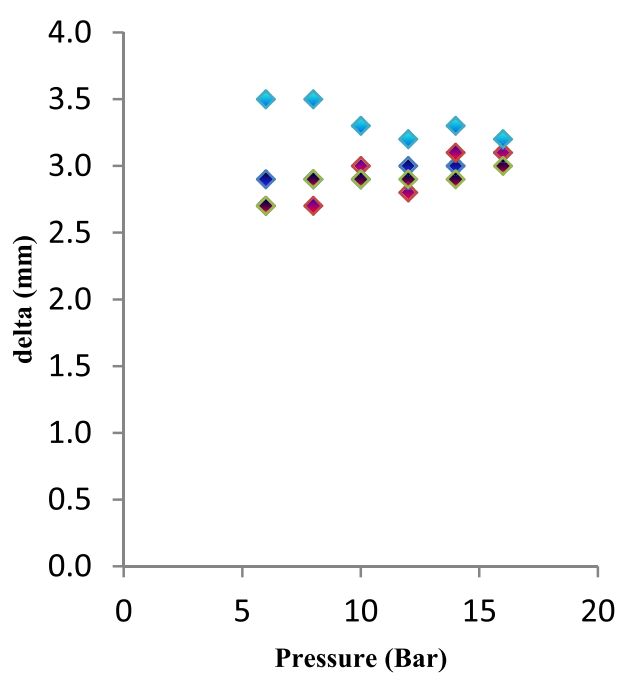

delta(1.5 g/l)

$-\operatorname{delta}(1.2 \mathrm{~g} / \mathrm{l})$

- $\operatorname{delta}(0.9 \mathrm{~g} / \mathrm{l})$

$\bullet \operatorname{delta}(0.3 \mathrm{gl})$

Fig. 8. Variation of delta versus $C_{o}$ and $P$.

the electronic orbital of the chemical entities (energy of Pauli) that have an important gradient (varying as $1 / r^{12}$ ) operating on closely distance.

\section{Polarization concentration $C_{m}$}

The developed model allows us also to calculate polarization concentration $C_{m}$ and its variation like it is illustrated in Figure 9.

The $C_{m}$ variation and the flux are in liner regression, as predicted, it increases with higher pressure and concentration. That can be explained by the importance of ion accumulation on the membrane surface.

\section{Concentration profile on the boundary layer polarization}

Knowing the polarization concentration $C_{m}$ and the thickness $\delta$, and taking to account the equations (5) and (10), we can determine the $\mathrm{CaCl}_{2}$ concentration on the polarization's boundary layer.

\section{Pressure effect}

The profiles of the concentrations in the polarization boundary layer are larger for the higher pressures; phenomenon is due to the fact that more pressure is important more the flow is high, and therefore the accumulation of particles will be the biggest (Fig. 10).

\section{Concentration effect}

In this case, pressure is maintained constant while initial concentrations $C_{o}$ are varying (Fig. 11).

The concentration profile in the polarization's boundary layer influences the variation of $C_{m}$ for higher pressures applied for different initial concentrations. The same effect is observed as that of the case of pressure, for the highest initial concentrations we notice an increase in the concentration profile.

These results have been confirmed by several studies; Chaabane et al. [26] found the same profile of the

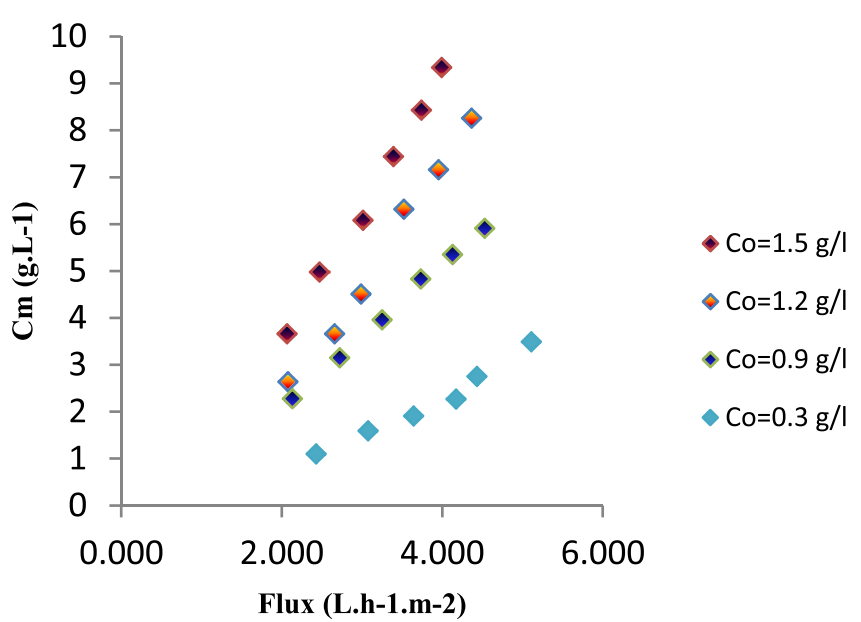

Fig. 9. Variation of $C_{m}$ versus $C_{o}$ and flux.

concentration profile in the polarization boundary layer for several salts and that the polarization concentration increased when the pressure increased. Déon et al. [27] investigated the effect of increasing concentration and pressure on the membrane charge density as well as on the pores and found that the polarization phenomenon was amplified.

The main advantage of this model is its simplicity to describe these phenomena with the knowledge of the initial concentrations in the solutions and the applied pressures. It can be shown that the obtained concentration profile is considered as the result between convection and retro-diffusion of ions.

\section{Highlighting of the mass transfer rate by convection and backscattering}

It is all perfectly clear that the convective mass transfer is much higher than the transfer by backscattering, otherwise each particle arriving at the membrane surface broadcasts immediately in the heart of the solution and we would have no accumulation of material, so the polarization phenomenon would disappear. To observe the backscattering material transfer effect on the polarization, it is necessary to decrease the transfer convection rate compared to backscattering. For this, the maximum applied pressure will be (16 bar) tolerated by our module at the beginning of material transfer, and then this pressure will gradually decrease up to 6 bar. The evolution of experimental length's boundary layer $\delta$ and concentration polarization $C_{m}$ are illustrated in Figures 12 and 13 .

Knowing $C_{m}$ and $\delta$ we can be acquainted with the evolution of the profile's solution concentration in the polarization boundary layer (Fig. 14).

During the pressure reduction, the evolution of $\delta$ indicates that the latter continues to increase. In addition, the concentration polarization $C_{m}$ increases proportionally when the pressure fluctuates between 16 and 14 bar. Thereafter, it continues to decline with decreasing pressure. 


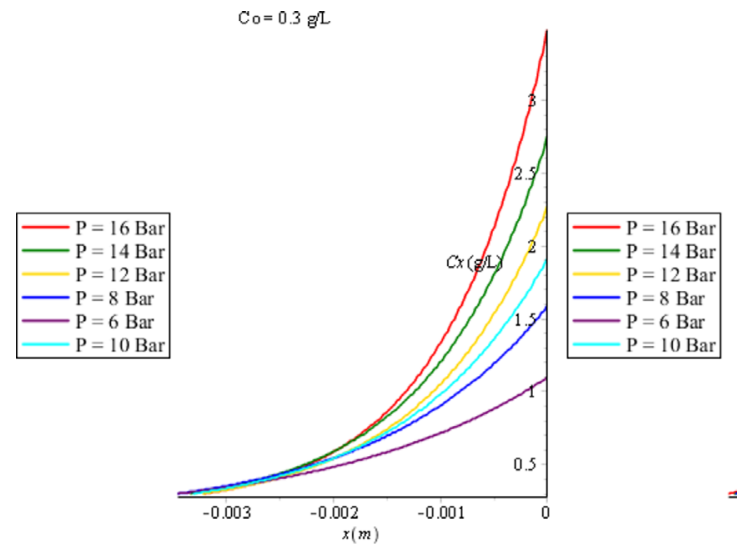

(a)

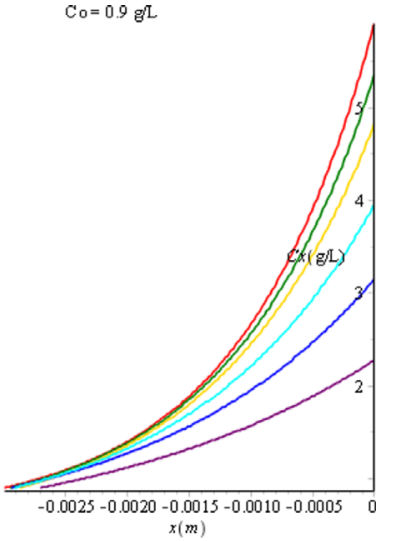

(b)

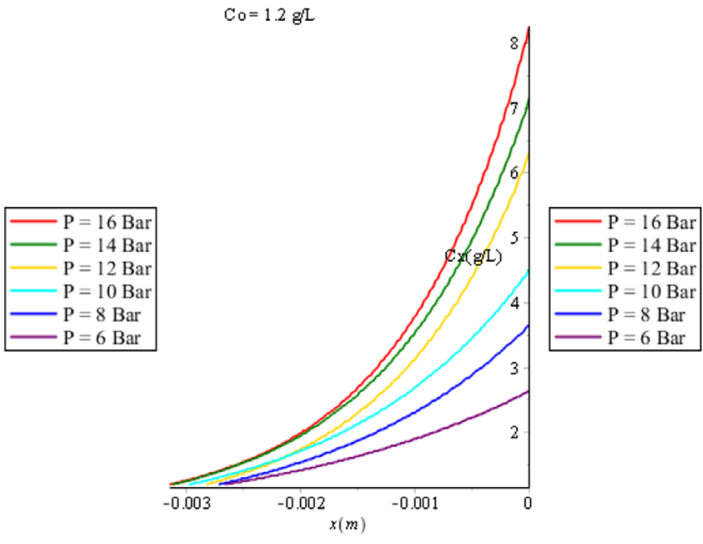

(c)

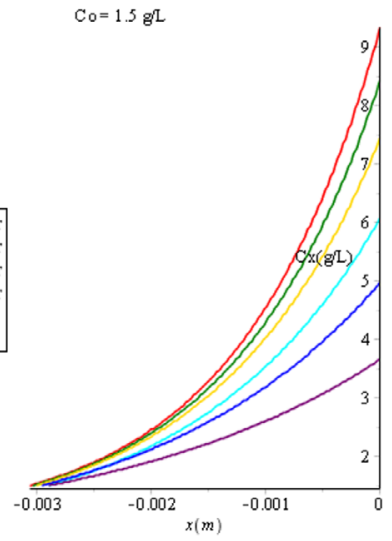

(d)

Fig. 10. Influence of pressure on spatial distribution of the solution concentration on the polarization boundary layer: (a) $C_{o}=0.3 \mathrm{~g} \mathrm{~L}^{-1}$, (b) $C_{o}=0.9 \mathrm{~g} \mathrm{~L}^{-1}$, (c) $C_{o}=1.2 \mathrm{~g} \mathrm{~L}^{-1}$, and (d) $C_{o}=1.5 \mathrm{~g} \mathrm{~L}^{-1}$.

The evolution of $C_{m}$ and $\delta$ affect directly the concentration profile in the polarization layer. Besides, based on Figure 14, we found that the value of the concentration within the boundary layer $C_{x}$ grows from 16 to 10 bar and decreases from 8 to 6 bar.

We can say that these phenomena made by fact of applying a pressure equal 16 bar, we compressed the maximum $\delta$ boundary layer length which is equal to $1.7 \mathrm{~mm}$ and convective transfer is at its maximum. By decreasing the pressure, we will reduce the convective transfer; also, it is even more important than the transfer by backscatter and this is why $C_{m}$ and $\delta$ continue to increase. From 12 bar, the mass transfer phenomenon will change the direction of variation; it is the balance transfer between the phenomenon of convection and diffusion.

At 10 bar, the transfer by backscattering slightly exceeds than the convection. We found that the concentration polarization decreases while $\delta$ continues to increase. It may also be noted that from 8 bar, $C_{m}$ decreases and $\delta$ continues to increase when the transfer by backscattering becomes very important, besides of convection, indeed each particle arriving within the boundary layer will be transferred in the heart of the solution and its transfer's speed is proportional to the transferring and the diffusion. Subsequently, the concentration $C_{x}$ within the boundary layer decreases progressively when the pressure $P$ declines. This is confirmed in Figure 14, when the growth of concentration $C_{x}$ profile was reported $P=8-6$ bar.

\section{Model validation: comparative study}

Theoretical salts rejections were calculated by equations (30) and (34), by using estimated $\delta$ and $C_{m}$. Figure 15 shows a comparison between the model's predictions and the experimental results at different concentrations. The figures show that there is an excellent agreement between experimental data and theoretical calculated rejection using our model.

The Figure 16 shows the zones of variations of the retention rate according to equation (34) where $R_{\text {obs }}$ is a function of delta and $C_{m}$ (this figure was obtained using the software "TableCurve 3D v4.0"). Indeed for the low values of $C_{m}$ the most important retention rates have been reported, but there is a reduction in retention rates when the phenomenon of polarization is important. 


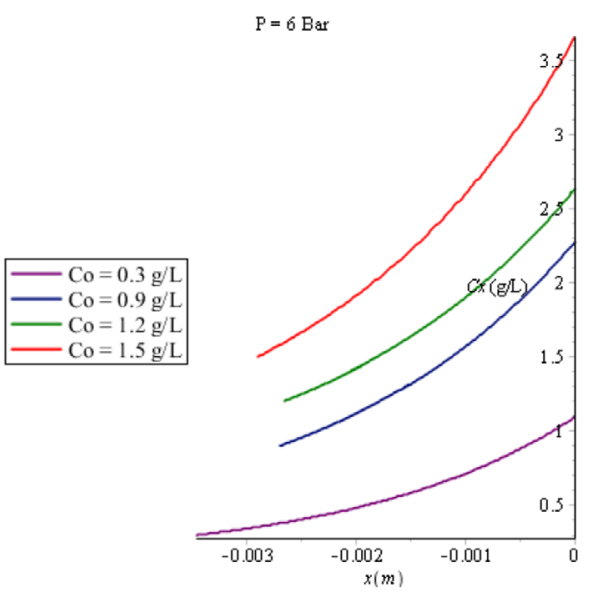

(a)



(c)

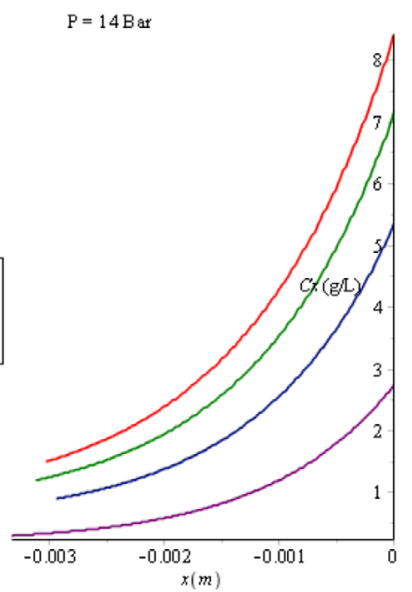

(e)

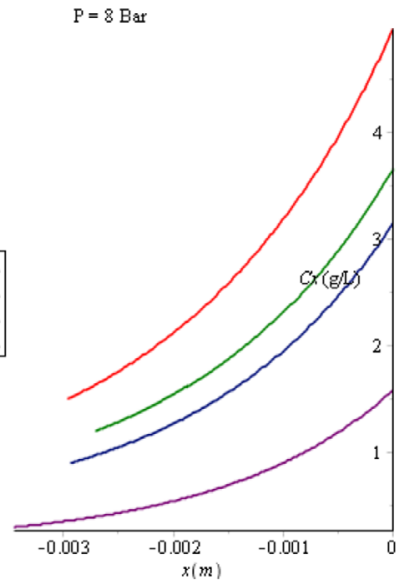

(b)

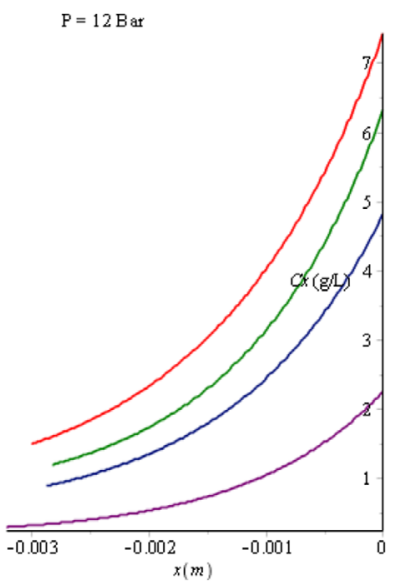

(d)

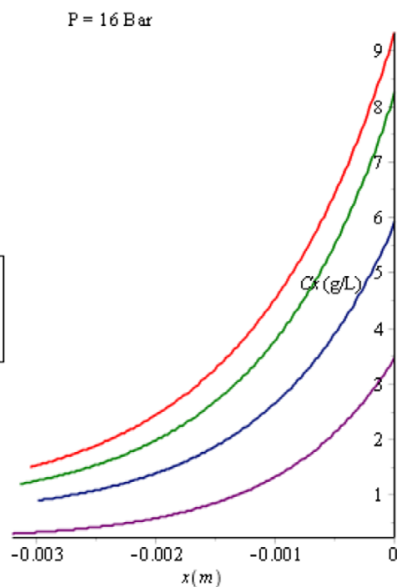

(f)

Fig. 11. Influence of initial concentration on spatial distribution concentration on the boundary layer polarisation (a) 6 bar, (b) 8 bar, (c) 10 bar, (d) 12 bar, (e) 14 bar, and (f) 16 bar. 




Fig. 12. Effect of decreasing of pressure on delta.



Fig. 13. Effect of decreasing the pressure on $C_{m}$.

\section{Conclusion}

This paper focused on the application of the dead-end filtration on nanofiltration membrane of synthetic ionic solutions. The phenomenon of polarization in the boundary layer and pressure effects were investigated. In this study, a new model has been established that allows determining the thickness of the polarization's boundary layer $(\delta)$ and the concentration of polarization $\left(C_{m}\right)$ at the membrane-solution interface.

It allowed us to determine the mathematical expression of the concentration profile in the polarization's boundary layer $\left(C_{x}\right)$. Applying this model to the $\mathrm{CaCl}_{2}$

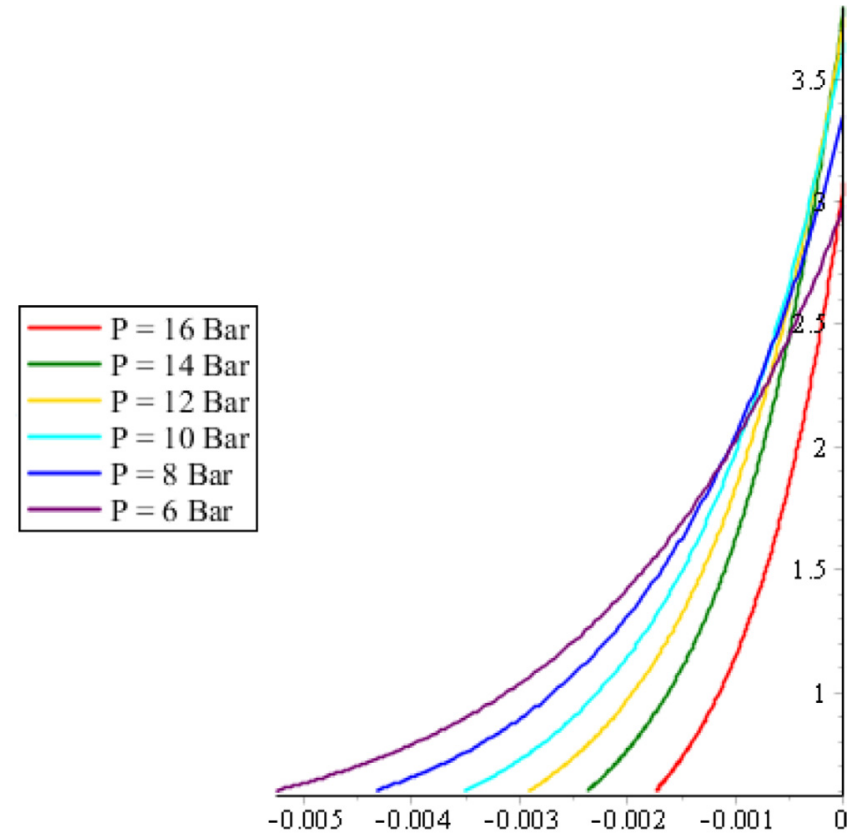

Fig. 14. Concentration profile in the polarization boundary layer of the $\mathrm{CaCl}_{2}$ solution at $0.6 \mathrm{~g} \mathrm{~L}^{-1}$ with decreasing variation of the pressure.



Fig. 15. Comparison between predicted and experimental values of the rejection rates.

solution, we were able to follow during the filtration the variation of the concentration profile in the polarization's boundary layer versus the applied pressure and the initial concentration of the solution. This made possible the identification of the mass transfer rate by convection and by retro-diffusion also to follow the evolution of 


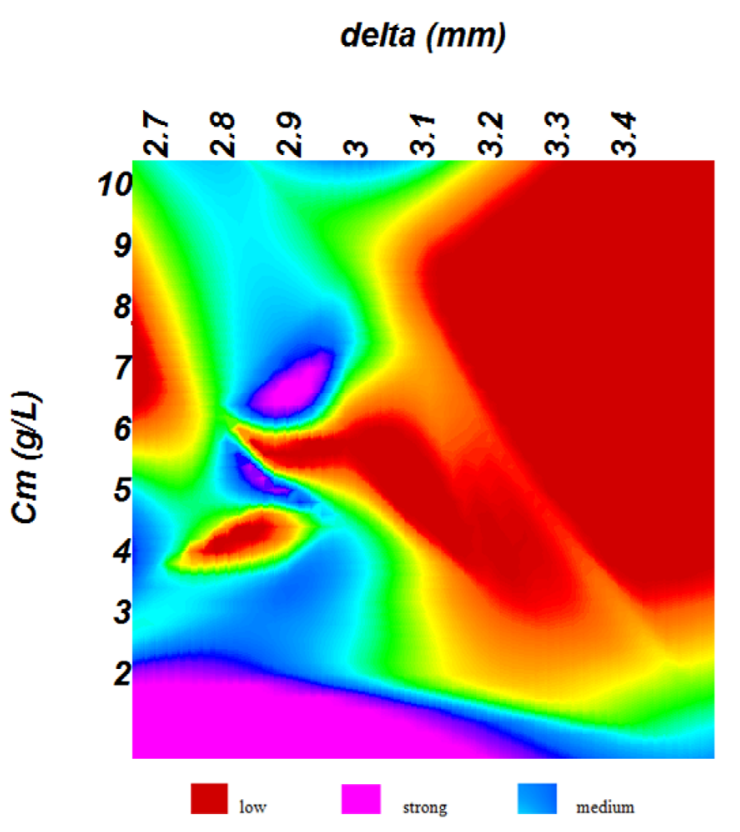

Fig. 16. Variation of the retention rate $R$ versus $C_{m}$ and delta.

polarization parameters due to the competition between the two phenomena. Finally, this model was validated for the comparison between the experimental retention rates data and the computed one.

\section{List of symbols}

$C_{o} \quad$ Concentration of ionic solution $\left(\mathrm{g} \mathrm{L}^{-1}\right)$

$C_{b} \quad$ Bulk concentration $\left(\mathrm{g} \mathrm{L}^{-1}\right)$

$C_{r} \quad$ Concentration of the retentate solution $\left(\mathrm{g} \mathrm{L}^{-1}\right)$

$C_{p} \quad$ Concentration of the permeate solution $\left(\mathrm{g} \mathrm{L}^{-1}\right)$

$C_{x} \quad$ Concentration profile in the boundary layer polarization

$C_{m} \quad$ Concentration of polarization $\left(\mathrm{g} \mathrm{L}^{-1}\right)$

$v_{x} \quad$ Elementary volume corresponding to the concentration $C_{x}\left(\mathrm{~m}^{3}\right)$

$V_{s} \quad$ Volume of solution $\left(\mathrm{m}^{3}\right)$

$\delta \quad$ Thickness of the boundary layer polarization $(\mathrm{m})$

$j \quad$ Mass flow $\left(\mathrm{g} \mathrm{h}^{-1} \mathrm{~m}^{-2}\right)$

$J \quad$ Volume flow $\left(\mathrm{L} \mathrm{h}^{-1} \mathrm{~m}^{-2}\right)$

$D \quad$ Diffusion coefficient $\left(\mathrm{m}^{2} \mathrm{~s}^{-1}\right)$

$t \quad$ Total filtration time $(\mathrm{s})$

$T \quad$ Filtration period time (s)

$l \quad$ Depth of the solution in the filtration module $(\mathrm{m})$

$x \quad$ Distance to the membrane surface $(\mathrm{m})$

$R_{\text {obs }}$ Retention rate observed

$R_{\text {int }} \quad$ Retention rate intrinsic

$L_{p} \quad$ Permeability $\left(\mathrm{L} \mathrm{h}^{-1} \mathrm{~m}^{-2} \mathrm{bar}^{-1}\right)$

$k \quad$ Constant $\alpha \quad$ Constant

$\beta \quad$ Constant

$\gamma \quad$ Constant

a Constant

$b \quad$ Constant

c Constant

$k_{1} \quad$ Constant

$k_{2} \quad$ Constant

\section{Conflict of interest}

The authors declare no competing interests.

\section{References}

1. Mulder M (1997), Basic principles of membrane technology, 2nd ed., Kluwer Academic Publishers, Netherlands.

2. Rosa MJ, de Pinho MN (1994), Separation of organic solutes by membrane pressure-driven processes. J Membr Sci 89, $235-243$.

3. Nystrom M, Kaipia L, Luque S (1995), Fouling and retention of nanofiltration membranes. J Membr Sci 98, 249-262.

4. Rosa MJ (1995), Separaçao selectiva de compostos organicos de correntes aquosas por ultrafiltraçao e nanofiltraçao, PhD thesis, Universidade Tecnica de Lisboa, Instituto Superior Tecnico, Lisboa.

5. Chaufer B, Baudry-Rabiller M, Guihard L, Daufin G (1996), Retention of ions in nanofiltration at various ionic strength. Desalination 104, 37-46.

6. Schaep J, Van der Bruggen B, Vandecasteele C, Wilms D (1998), Influence of ion size and charge in nanofiltration. Separ Purif Technol 14, 155-162.

7. Peeters JMM, Mulder MHV, Strathmann H (1999), Streaming potential measurements as a characterization method for nanofiltration membranes. Colloids Surf A: Physicochem Eng Aspects 150, 247-259.

8. Childress AE, Elimelech M (2000), Relating nanofiltration membrane performance to membrane charge (electrokinetic) characteristics. Environ Sci Technol 34, 3710-3716.

9. Costa AR, de Pinho MN (2006), Performance and cost estimation of nanofiltration for surface water treatment in drinking water production. Desalination 196, 55-65.

10. Paugam L, Taha S, Cabon J, Dorange G (2003), Elimination of nitrate ions in drinking waters by nanofiltration. Desalination 152, 271-274.

11. Hilal N, Al-Zoubi H, Mohammad AW, Darwish NA (2005), Nanofiltration of highly concentrated salt solutions up to seawater salinity. Desalination 184, 315-326.

12. Lhassani A, Rumeau M, Benjelloun D, Pontie M (2001), Selective demineralization of water by nanofiltration application to the defluorination of brackish water. Water Res 35, 3260-3264.

13. Van der Bruggen B, Vandecasteele C (2003), Removal of pollutants from surface water and groundwater by nanofiltration: overview of possible applications in the drinking water industry. Environ Pollut 122, 435-445.

14. Hilal N, Al-Zoubi H, Darwish NA, Mohammad AW, Abu Arabi M (2004), A comprehensive review of 
nanofiltration membranes: treatment, pretreatment, modelling, and atomic force microscopy. Desalination 170 , 281-308.

15. Ahmadzadech S, Dolatabadi M (2018), Modeling and kinetics study of electrochemical peroxidation process for mineralization of bisphenol A; a new paradigm for groundwater treatment. J Mol Liquids 254, 76-82.

16. Ahmadzadech S, Dolatabadi M (2018), In situ generation of hydroxyl radical for efficient degradation of 2,4-dichlorophenol from aqueous solutions. Environ Monit Assess 190, 340.

17. Ahmadzadech S, Asadipour A, Yoosefian M, Dolatabadi M (2017), Improved electrocoagulation process using chitosan for efficient removal of cefazolin antibiotic from hospital wastewater through sweep flocculation and adsorption: kinetic and isotherm study. Desalin Water Treat 92, $160-171$.

18. Van der Bruggen B, Manttari M, Nystrom M (2008), Drawbacks of applying nanofiltration and how to avoid them: a review. Sep Purif Technol 63, 251-263.

19. Krishna R, Wesselingh JA (1997), The Maxwell-Stefan approach to mass transfert. Chem Eng Sci 52, 861-911.

20. Spiegler KS, Kedem O (1966), Thermodynamics of hyperfiltration (reverse osmosis): criteria for coefficient membranes. Desalination 1, 311-326.
21. Wang XL, Tsuru T, Nakao S, Kimura S (1995), Electrolyte transport through nanofiltration membranes by the spacecharge model and the comparison with Teorell-MeyerSievers model. J Membr Sci 103, 117-133.

22. Shang W-J, Wang X-L, Yu Y-X (2006), Theoretical calculation on the membrane potential of charged porous membranes in 1-1, 1-2, 2-1 and 2-2 electrolyte solutions. J Membr Sci 285, 362-375.

23. Donnan F (1995), Theory of membrane equilibria and membrane potentials in the presence of non-dialysing electrolytes. J Membr Sci 100, 45-55.

24. Eriksson P (1988), Nanofiltration extends the range of membrane filtration. Environ Prog 7, 58-62.

25. Tsuru T, Urairi M, Nakao SI, Kimura S (1991), Negative rejection of anions in the loose reverse osmosis separation of mono-and divalent ion mixtures. Desalination 81, 219-227.

26. Chaabane T, Taha S, Ahmed TM, Maachi R, Dorange G (2007), Coupled model of film theory and the NernstPlanck equation in nanofiltration. Desalination 206, 424-432.

27. Déon S, Escoda A, Fievet P (2011), A transport model considering charge adsorption inside pores to describe salts rejections by nanofiltration membranes. Chem Eng Sci 66, 2823-2832.

Cite this article as: Mdemagh Y, Hafiane A, Ferjani E. (2018), Characterization and modeling of the polarization phenomenon to describe salt rejection by nanofiltration. 4open, $\mathbf{1}, 5$. 